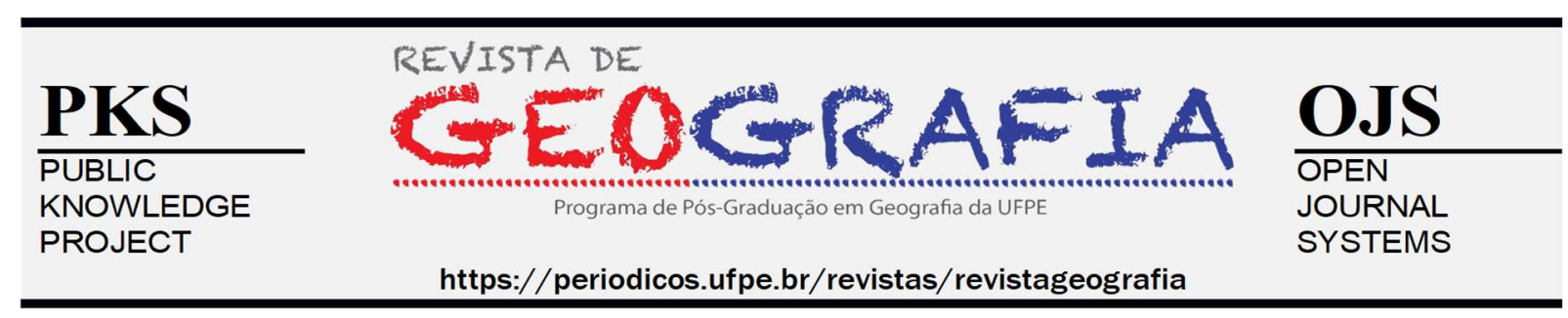

\title{
AGRONEGÓCIO E RELAÇÕES CAMPO-CIDADE NO CEARÁ
}

\author{
Denise Elias $^{1}$, Felipe Rodrigues Leitão ${ }^{2}$ \\ ${ }^{1}$ Doutora em Geografia Humana, Professora do Programa de Pós-Graduação em Geografia da UECE, \\ Pesquisadora do CNPq. E-mail: deniseliasgeo@gmail.com-ORCID: http://orcid.org/0000-0002-8384-0990 \\ ${ }^{2}$ Geógrafo, Mestrando do Programa de Pós-Graduação em Geografia da UECE. E-mail: mr.feliper@gmail.com \\ - ORCID: http://orcid.org/0000-0001-7682-3351
}

Artigo recebido em 23/07/2020 e aceito em 02/08/2020

Resumo: A difusão do agronegócio globalizado no Ceará tem sido intensa nas últimas três décadas. Desse modo, este artigo analisa as relações campo-cidade estabelecidas nesse estado a partir da agroindústria alimentar, entendendo-a como parte desse agronegócio. A metodologia consistiu em pesquisa bibliográfica, organização de séries históricas sobre estabelecimentos e empregos industriais, trabalhos de campo e organização de uma hemeroteca. Concluímos que, por um lado, com a difusão do agronegócio no Ceará, parte da produção agropecuária está fortemente monopolizada pelo capital industrial e, por outro, que a formação de empresas monopolistas no setor da agroindústria alimentar está em crescimento. Assim, as empresas monopolistas são variável-chave para melhor compreender os processos associados ao agronegócio no Ceará.

Palavras-chave: Agronegócio, Agroindústria alimentar, Relações campo-cidade, Ceará.

\section{AGRIBUSINESS AND CAMP-CITY RELATIONS IN CEARÁ}

Abstract: The spread of globalized agribusiness in Ceará has been intense in the last three decades. That way, this article analyses camp-city relations established in thise state from the food agroindustry, understanding it as part of this agribusiness. The methodology consisted of bibliographic research, organization of historical series on industrial establishments and jobs, fieldwork, and organization of a newspaper library. We concludet that, on the one hand, with the dissemination of agribusiness in Ceará, part of agricultural production is strongly monopolized by industrial capital, and, on the other, that the formation of monopolistic companies in the agro-food industry is growing. Thus, the monopoly companies key variable to acquire a better understanding of the processes associated with agribusiness in Ceará.

Key-words: Agribusines, Agro-food industry, camp-city relations, Ceará. 


\section{INTRODUÇÃO ${ }^{1}$}

A expansão do capitalismo monopolista se dá, dentre outras maneiras, através da sujeição da agricultura à indústria. ${ }^{2}$ No Brasil, esse processo é bastante evidente e hoje são inúmeros os ramos de produção agropecuária monopolizados pelo capital industrial, especialmente pelas agroindústrias. Por agroindústria entendemos as atividades industriais de beneficiamento, processamento e/ou transformação de matérias-primas originadas na agropecuária (alimentos, bebidas, papel e celulose etc.).

A reestruturação produtiva da agropecuária (ELIAS, 2003a, 2013, 2017) das últimas cinco décadas é paralela a uma significativa modificação do perfil do setor industrial brasileiro, sendo a expansão da agroindústria um dos aspectos deste processo, notadamente desde a década de 1970. Esta se deu dentro de um contexto mais amplo, no qual um conjunto de políticas econômicas visava promover as exportações de bens manufaturados ou semimanufaturados, entre os quais se incluíam os de produtos agroindustriais (ELIAS, 2003a).

Diante do exposto, entendemos que a agroindústria se constitui numa das variáveischave para os estudos sobre as relações campo-cidade, de forma singular se as consideramos através dos circuitos espaciais da produção e círculos de cooperação (SANTOS, 1996). São inúmeros os fluxos de matéria e de informação, entre os locais da produção agropecuária e o da transformação industrial, das sedes corporativas destas empresas, dos escritórios de exportação, das estações de pesquisa agropecuária, dos portos e aeroportos e todos os demais comércios e serviços associados ao consumo produtivo (SANTOS, 1988) do agronegócio globalizado (ELIAS, 2003a, 2015, 2017). Estes formam verdadeiras redes geográficas nas palavras de Correa (2014), às quais temos chamado de redes agroindustriais (ELIAS, 2008), para o caso dos estudos sobre o agronegócio globalizado.

No Ceará, historicamente, a agroindústria se destaca em meio à indústria de transformação, tanto no total de estabelecimentos, quanto no número de empregos, sobretudo a agroindústria alimentar, que é responsável por parte significativa do PIB industrial do estado.

\footnotetext{
${ }^{1} \mathrm{O}$ presente artigo é uma versão revisada de trabalho aceito e publicado nos Anais do Encontro Nacional de Geografia Agrária (ENGA), ocorrido em 2018, na Universidade Federal da Grande Dourados (UFGD), em Dourados, Mato Grosso do Sul. E resulta de uma pesquisa maior sobre o agronegócio globalizado no Ceará.

${ }^{2}$ Sobre o tema ver Oliveira (2010).
} 
Inferimos, então, que o estudo desse ramo industrial constitui um vetor importante para o estudo das relações campo-cidade hoje vigentes no estado. Dessa forma, neste artigo, temos como principal objetivo evidenciar as relações campo-cidade no Ceará estabelecidas a partir da agroindústria alimentar.

Como metodologia adotamos alguns procedimentos clássicos da pesquisa científica, tais como a pesquisa bibliográfica; a seleção de variáveis (estabelecimentos e empregos industriais) e organização de séries históricas, tendo como recorte temporal meados dos anos 1990 até o presente, sendo os dados trabalhados para os anos de 1996, 2006 e 2016; trabalhos de campo; organização de uma hemeroteca com documentos considerando temas, processos, agentes de interesse para a pesquisa; sistematização e análise do material organizado. Como recorte espacial tivemos o estado do Ceará.

Além desta introdução e das considerações finais, o artigo é composto por três seções que apresentam alguns resultados da pesquisa em andamento sobre o agronegócio no Ceará. A primeira faz uma breve contextualização da relevância da relação da agropecuária com a indústria no estado. A segunda descreve o perfil da agroindústria cearense. A terceira apresenta evidências das relações campo-cidade de várias naturezas que se dão no Ceará. Para tanto, selecionamos algumas importantes empresas cearenses da agroindústria alimentar.

\section{AGROPECUÁRIA E INDÚSTRIA}

A agropecuária, o extrativismo e a pesca sempre tiveram peso determinante na economia do Ceará. Até final dos anos 1990, a hegemonia era de culturas tradicionais voltadas ao consumo alimentar (feijão, arroz, milho, mandioca, em especial) e alguns produtos destinados à exportação (castanha de caju, cera de carnaúba, lagosta). A maior parte produzida em estabelecimentos de pequenas dimensões, de forma extensiva, com sistemas técnicos agrícolas tradicionais, mais associadas aos ditames e aos ritmos da natureza do semiárido. Durante séculos e até muito recentemente, o modo de vida do sertanejo, em grande parte relacionado à biodiversidade deste bioma, foi predominante no estado. Mas desde a década de 1990 há uma difusão do agronegócio globalizado com muitos e profundos impactos na economia, na produção do espaço e no modo de vida. ${ }^{3}$

\footnotetext{
${ }^{3}$ Sobre a difusão do agronegócio no Ceará ver Elias (1999, 2002a, 2002b, 2003b).
} 
Como ocorre em todo o semiárido nordestino, as atividades industriais estiveram associadas intrinsecamente ao aproveitamento de seus recursos naturais, notadamente através da transformação de produtos agropecuários e do extrativismo vegetal. Evidencia-se, assim, que parte importante das indústrias tem nestes a fonte principal de matéria-prima, o que por si só já evidencia inúmeras conexões entre o campo e a cidade, especialmente considerando que parte significativa das agroindústrias localiza-se na cidade.

Podemos mesmo dizer que, para o caso cearense, as origens dessa associação remontam ao período colonial, com a criação de gado (couros e peles). Posteriormente, no século XVIII e principalmente no século XIX, com o cultivo de algodão e sua transformação industrial, já em bases mais modernas e voltada para exportação (indústria de fiação e têxtil). Nesta época, surgem alguns outros ramos associados, como o de óleos vegetais obtidos através do algodão, mas também de outras espécies nativas, tais como da oiticica e da mamona.

O setor industrial do estado tem outro de seus marcos nos anos 1950 e 1960, período no qual tomava corpo o debate sobre as desigualdades regionais e as possíveis formas de eliminálas, sendo a região Nordeste o centro de parte de tais debates, vista como "região problema". As políticas públicas idealizadas no período mencionado propunham um desenvolvimento regional baseado na industrialização, como forma de dar novo impulso à economia local e integrá-la à nacional.

Destacou-se, nesse momento, a atuação da Superintendência de Desenvolvimento do Nordeste (Sudene), órgão federal criado em 1958 para orientar e gerir os investimentos públicos direcionados à região. Os incentivos fiscais eram a principal ferramenta operada, sendo direcionados à modernização e ampliação de empresas já existentes, assim como a implantação de novas plantas indústrias. Tais políticas deram grande impulso ao setor industrial cearense, notadamente ao agroindustrial (OLIVEIRA, 1993).

Vários autores já destacaram que foram dois os momentos importantes na política de incentivos à industrialização orquestrados pela Sudene no Ceará. O primeiro, no início da década de 1960, a partir do Artigo 34/184, incentivando a atividade industrial cuja base estava no capital e matéria-prima locais, o que afetou sobremaneira as atividades industriais já tradicionalmente praticadas no estado, como as da agroindústria alimentar e a de vestuário, que

\footnotetext{
${ }^{4}$ Artigo 34 do decreto Lei n. ${ }^{\circ} 3995$ de dezembro de 1961 e as emendas introduzidas pelo artigo 18 do Decreto Lei n. ${ }^{\circ} 4239$ de junho de 1963. Este instituía a possibilidade de as empresas reduzirem seus impostos de renda anuais em $50 \%$ possibilitando a capitalização de projetos industriais.
} 
figuram entre as mais beneficiadas, o que em parte reforçou os poucos grupos econômicos existentes.

O segundo momento é o inaugurado pelo Fundo de Investimento do Nordeste (Finor), em 1974, sendo considerado o "berço da industrialização cearense" (ABU-EL-HAJ, 1997). Neste contexto, o Ceará figurou entre os três estados da região Nordeste que mais receberam incentivos fiscais do conjunto Artigo 34/18 e FINOR ${ }^{5}$, como aponta Ferreira (1995). Vale lembrar que os investimentos deste período também serviram, em grande parte, para fortalecer as agroindústrias tradicionais.

A economia cearense, até então fortemente baseada na agropecuária, passou por uma mudança de perfil. Com as políticas de incentivos fiscais, a atividade industrial ganhou mais peso. Porém, é necessário levar em consideração que isso não promoveu uma mudança radical nas estruturas produtivas locais, uma vez que se beneficiaram desse processo as atividades industriais tradicionalmente desenvolvidas no estado, ou seja, aquelas associadas às materiais primas locais (AMORA, 1994).

No que tange às ações do Poder Executivo do Ceará, uma ferramenta implantada foi o Fundo de Desenvolvimento Industrial (FDI), de 1979, que ao longo do tempo se consolida como uma importante política de fomento industrial no estado. Ao FDI associa-se um conjunto de programas e suas modalidades visam a implantação, ampliação, diversificação, modernização e recuperação de empresas, tendo se consolidado como um dos principais instrumentos de atração de indústrias para o Ceará. Cada programa soma uma gama significativa de benefícios, destacando-se a renúncia fiscal, para a instalação de empreendimentos industriais. ${ }^{6}$

A década de 1990 se configura como um ponto de inflexão para a efetiva consolidação desses programas, que através de uma série de benefícios e concessões fiscais, transformou o Ceará em um dos mais aguerridos representantes de uma verdadeira guerra fiscal entre os

\footnotetext{
${ }^{5}$ Além do Ceará, os outros estados que mais receberam recursos provenientes do FINOR foram Bahia e Pernambuco.

${ }^{6}$ Os principais programas são: o Programa de Incentivo ao Desenvolvimento Industrial (Provin): até $75 \%$ do ICMS devido; retorno de 1\% a 25\%; o Programa de Atração de Empreendimentos Estratégicos (Proade): até 99\% do ICMS relativo às operações de produção própria da empresa; retorno de até 1\%; o Programa de Incentivos à Centrais de Distribuição de Mercadorias do Ceará (PCDM): até 75\% do ICMS gerado nas saídas interestaduais de mercadorias; diferimentos: ativo fixo 100\%; matéria-prima até 100\%; ASTC; o Programa de Incentivos da Cadeia Produtiva Geradora de Energias Renováveis (PIER): 75\% do ICMS recolhido mensalmente e dentro do prazo legal; retorno de $1 \%$. Cada programa apresenta suas especificidades, objetivos e público alvo. Disponível em: $\quad<$ https://www.adece.ce.gov.br/2014/06/11/incentivos-fundo-de-desenvolvimento-industrial-fdi/>. Acesso em: 18 jul. 2020.
} 
estados pelos investimentos produtivos, deixando bastante evidente o que Santos (1994) chamou de guerra dos lugares.

Apesar de todas as concessões e renúncias fiscais realizadas e de efetivamente ter ocorrido atração de alguns importantes investimentos, sendo o das indústrias de calçados e da Companhia Siderúrgica do Pecém (CSP) entre os exemplos mais concretos, os investimentos públicos continuaram também atuando em benefício de ramos de atividade já praticados, dentre os quais o da agroindústria, que se destaca ainda hoje como uma das principais atividades econômicas no Ceará.

\section{PERFIL DA AGROINDÚSTRIA ${ }^{7}$}

Considerando a relevância da agroindústria na economia do Ceará, utilizamos a Classificação Nacional de Atividades Econômicas $(\mathrm{CNAE})^{8}$ para identificar os grupos de indústria de transformação que seriam correspondestes às agroindustriais e chegamos a um conjunto de 16 grupos de atividades. ${ }^{9}$ Para atingir as atividades predominantes no estado, agrupamos esse conjunto em dois ramos: o alimentar e o não alimentar. Enquanto o último soma sete grupos, o alimentar é formado por nove grupos de atividade industrial, conforme apresentado no Quadro 1. Vale destacar que cada grupo se desdobra em uma gama de classes de atividades industriais.

Quadro 1 - Ceará: ramos e grupos da agroindústria

\begin{tabular}{|l|l|}
\hline \multicolumn{1}{|c|}{ Ramos } & \multicolumn{1}{c|}{ Grupos } \\
\hline \multirow{4}{*}{ Agroindústria Alimentar } & Fabricação de outros produtos alimentícios \\
\cline { 2 - 2 } & Fabricação de bebidas \\
\cline { 2 - 2 } & $\begin{array}{l}\text { Moagem, fabricação de produtos amiláceos e de rações } \\
\text { balanceadas para animais }\end{array}$ \\
\cline { 2 - 2 } & $\begin{array}{l}\text { Processamento, preservação e produção de conservas de } \\
\text { frutas, legumes e outros vegetais }\end{array}$ \\
\cline { 2 - 2 } & Abate e preparação de produtos de carne e de pescado \\
\hline
\end{tabular}

\footnotetext{
${ }^{7}$ A organização do banco de dados estatístico sobre a agroindústria foi um trabalho coletivo realizado no desenvolvimento de projeto sobre o agronegócio no Ceará coordenado por Denise Elias. Para a concepção e organização da estrutura para o armazenamento das informações, contamos com a colaboração do arquiteto Henrique Alves da Silva. Da mesma forma, com o trabalho do aluno de graduação do curso de Geografia da Universidade Estadual do Ceará (UECE) Wenniton Almeida, como auxiliar de pesquisa.

${ }^{8}$ A Classificação Nacional de Atividades Econômicas (CNAE) é a classificação oficial adotada pelo governo brasileiro na identificação de atividades econômicas, cadastro e registro de empresas. Busca-se com sua institucionalização a padronização no fornecimento, coleta e disseminação de dados. A CNAE apresenta uma estrutura hierarquizada, tendo atualmente cinco níveis: seção, divisão, grupo, classe e subclasse. (IBGE, 2007).

${ }^{9}$ É importante destacar que a nossa seleção está diretamente associada aos objetivos da pesquisa sobre o agronegócio no Ceará e as atividades industriais existentes no estado.
} 


\begin{tabular}{|c|c|}
\hline & Laticínios \\
\hline & Torrefação e moagem de café \\
\hline & Fabricação e refino de açúcar \\
\hline & Produção de óleos e gorduras vegetais e animais \\
\hline \multirow{7}{*}{$\begin{array}{l}\text { Agroindústria não } \\
\text { alimentar }\end{array}$} & Fabricação de calçados de couro \\
\hline & Tecelagem - inclusive fiação e tecelagem \\
\hline & Fiação \\
\hline & Curtimento e outras preparações de couro \\
\hline & Fabricação de produtos do fumo \\
\hline & Beneficiamento de fibras têxteis naturais \\
\hline & Produção de álcool \\
\hline
\end{tabular}

Fonte: Elaborado pelos autores (2018) com base em informações da CNAE.

A partir da CNAE, recorremos aos dados da Relação Anual de Informações Sociais (RAIS), do Ministério do Trabalho e Emprego (MTE), ${ }^{10}$ para chegarmos ao número de estabelecimentos e de empregos dos respectivos grupos da agroindústria. Os dados atestaram a relevância da atividade no Ceará, de forma singular na concentração de empregos. Em 2016, as agroindústrias somavam perto de $19 \%$ de todos os estabelecimentos e $35 \%$ do total de empregos da indústria de transformação. Muito embora tenha perdido participação relativa em relação a 1996, a variação absoluta mostra um crescimento superior a $80 \%$ nos 20 anos considerados para análise em ambas as variáveis analisadas (Tabela 1), sendo que o número de estabelecimentos passa de 1.160 para 2.096 e o de empregos de 43.107 para 81.287.

Tabela 1 - Ceará: número de estabelecimentos e empregos da indústria de transformação e da agroindústria. 1996 e 2016

\begin{tabular}{l|rr|rr}
\hline & \multicolumn{2}{|c|}{ Estabelecimentos } & \multicolumn{2}{c}{ Empregos } \\
& 1996 & 2016 & 1996 & 2016 \\
\hline Indústria de transformação (A) & 4.390 & 11.146 & 107.371 & 232.501 \\
Agroindústria (B) & 1.160 & 2.096 & 43.107 & 81.287 \\
Participação B/A (\%) & 26,42 & 18,8 & 40,15 & 34,96 \\
\hline
\end{tabular}

Fonte: Elaborado pelos autores (2018) com base nos dados do MTE/RAIS.

\footnotetext{
10 A Relação Anual de Informações Sociais (RAIS) é um importante instrumento de coleta de dados socioeconômicos que toda pessoa jurídica e outros empregadores devem enviar ao Ministério do Trabalho e Emprego (MTE) brasileiro. Foi instituída pelo Decreto $\mathrm{n}^{\circ} 76.900$, de 23 de dezembro de 1975. Tem como objetivos suprir às necessidades de controle da atividade trabalhista no país, prover dados para a elaboração de estatísticas do trabalho e disponibilizar informações do mercado de trabalho às entidades governamentais. Disponível em: $<$ http://www.rais.gov.br/sitio/sobre.jsf>. Acesso em 18 jul. 2020.
} 
O ramo da agroindústria alimentar, por sua vez, mostra-se bastante expressivo no conjunto da agroindústria cearense, representando $88,55 \%$ dos estabelecimentos e $53 \%$ dos empregos para o ano de 2016, como mostra a Tabela 2.

Tabela 2 - Ceará: número de estabelecimentos e empregos da agroindústria segundo os seus ramos. 1996, 2016

\begin{tabular}{l|rrrr|rrrr}
\hline Ramo & \multicolumn{2}{|c}{$\mathbf{1 9 9 6}$} & \multicolumn{2}{c|}{$\mathbf{2 0 1 6}$} & \multicolumn{2}{c}{$\mathbf{1 9 9 6}$} & \multicolumn{2}{c}{$\mathbf{2 0 1 6}$} \\
& Qtde. & \% & Qtde. & \% & Qtde. & \% & Qtde. & \multicolumn{1}{c}{$\%$} \\
\hline $\begin{array}{l}\text { Agroindústria } \\
\text { Alimentar }\end{array}$ & 984 & 84,83 & 1.856 & 88,55 & 32.690 & 75,83 & 43.106 & 53,03 \\
$\begin{array}{l}\text { Agroindústria } \\
\text { não alimentar }\end{array}$ & 176 & 15,17 & 240 & 11,45 & 10.417 & 24,17 & 38.181 & 46,97 \\
\hline \multicolumn{1}{c}{ Total } & 1.160 & 100 & 2.096 & 100 & 43.107 & 100 & 81.287 & 100 \\
\hline
\end{tabular}

Fonte: Elaborado pelos autores (2018) com base nos dados do MTE/RAIS.

A mesma base de dados (MTE/RAIS) indica que a agroindústria é formada principalmente por microempresas (com até 19 empregados) e que, em 2016, elas somavam $79,5 \%$ do total de estabelecimentos agroindustriais. Destaca-se, porém, a importância dos estabelecimentos de grande porte (com mais de 499 empregados) ${ }^{11}$. Embora não representassem nem $1 \%$ do total de estabelecimentos agroindustriais no mesmo ano, concentravam $54 \%$ dos empregos $^{12}$.

Neste $1 \%$ estão estabelecimentos que se constituem como modernas empresas que, além do número de empregos, se notabilizam também pela capacidade produtiva instalada, pela complexidade de suas operações, pela grande quantidade de matéria-prima que movimentam, pelo poder que têm junto ao Estado de impor suas demandas de infraestrutura e incentivos fiscais, pela diversidade de atividades econômicas que exercem, pela atuação em diferentes escalas geográficas etc.

Fica evidente, desta forma, que tais empresas se constituem em importantes agentes de produção do espaço, devido à grande quantidade de fixos e fluxos (SANTOS, 1988) de várias naturezas e magnitudes a elas associados. Entre os processos inerentes a tais empresas, podemos

\footnotetext{
${ }^{11}$ Conforme o critério adotado pelo Instituto Brasileiro de Geografia e Estatística (IBGE), na Pesquisa Industrial Anual (PIA), os estabelecimentos industriais são classificados em: microempresa (até 19 pessoas ocupadas), pequena empresa (de 20 a 99 pessoas ocupadas), média empresa (de 100 a 499 pessoas ocupadas) e grande empresa (500 pessoas ocupadas ou mais) (IBGE, 2017).

${ }^{12}$ Fonte: MTE/RAIS, 2016.
} 
destacar as relações campo-cidade, incrementadas sobremaneira nas duas últimas décadas no Ceará.

Levando em consideração a importância do ramo alimentar da agroindústria e o destaque dos estabelecimentos de grande porte, intuímos que as grandes empresas da agroindústria alimentar são um excelente objeto de análise para desvendarmos inúmeros processos inerentes ao agronegócio globalizado no Ceará, entre eles as relações campo-cidade, que se multiplicaram nas duas últimas décadas. Dessa forma, selecionamos algumas das empresas mais destacadas neste ramo como objeto de análise e, efetivamente, foi possível vislumbrar várias redes geográficas (CORRÊA, 2014) por elas tecidas.

Considerando o total de estabelecimentos e de empregos que concentram perante o total da agroindústria alimentar, destacamos quatro grupos, especificamente: Laticínios; Abate e preparação de produtos de carne e de pescado; Fabricação de outros produtos alimentícios; Moagem, fabricação de produtos amiláceos e de rações balanceadas para animais. Esses quatro grupos, no ano de 2016, concentravam 80,26\% do total de estabelecimentos e 47,86\% dos empregos na agroindústria alimentar no Ceará, sendo o de Fabricação de outros produtos alimentícios o mais destacado quanto aos estabelecimentos e empregos.

Tabela 3 - Número de estabelecimentos e empregos dos grupos agroindustriais alimentares selecionados.

\begin{tabular}{|c|c|c|c|c|c|c|c|c|}
\hline \multirow{3}{*}{ Grupo } & \multicolumn{4}{|c|}{ Estabelecimentos } & \multicolumn{4}{|c|}{ Empregos } \\
\hline & \multicolumn{2}{|c|}{1996} & \multicolumn{2}{|c|}{2016} & \multicolumn{2}{|c|}{1996} & \multicolumn{2}{|c|}{2016} \\
\hline & Qtde & $\%$ & Qtde & $\%$ & Qtde & $\%$ & Qtde & $\%$ \\
\hline $\begin{array}{l}\text { Abate e preparação de } \\
\text { produtos de carne e de } \\
\text { pescado }\end{array}$ & 34 & 2,93 & 94 & 4,48 & 553 & 1,28 & 2.760 & 3,4 \\
\hline $\begin{array}{l}\text { Fabricação de outros } \\
\text { produtos alimentícios }\end{array}$ & 642 & 55,34 & 1.100 & 52,48 & 11.299 & 26,21 & 19.489 & 23,98 \\
\hline Laticínios & 100 & 8,62 & 185 & 8,83 & 882 & 2,05 & 2.915 & 3,59 \\
\hline $\begin{array}{l}\text { Moagem, fabricação de } \\
\text { produtos amiláceos e de } \\
\text { rações balanceadas para } \\
\text { animais }\end{array}$ & 75 & 7,62 & 134 & 7,22 & 9.961 & 30,47 & 5.274 & 11,96 \\
\hline Total & 851 & 74,51 & 1.513 & 73,01 & 22.695 & 60,01 & 30.438 & 42,93 \\
\hline
\end{tabular}

Fonte: Elaborado pelos autores (2018) com base nos dados do MTE/RAIS. 


\section{RELAÇÕES CAMPO-CIDADE A PARTIR DAS AGROINDÚSTRIAS ALIMENTARES ${ }^{13}$}

O objetivo desta seção é apresentar evidências das inúmeras relações campo-cidade que se dão no estado do Ceará a partir de algumas de suas principais empresas agroindustriais alimentares.

Considerando a importância do grupo de Laticínios, notadamente a classe de Preparação do leite, fabricação de produtos do laticínio, os exemplos serão de duas das mais importantes empresas associadas: a Betânia Lácteos e a Cooperativa Agrícola Mista de Maranguape Ltda. Juntas elas consomem cerca de $70 \%$ de todo o leite in natura produzido no Ceará, ${ }^{14}$ o que por si só já mostra a grande capilaridade das relações campo-cidade estabelecidas por estas duas empresas, especialmente considerando que as bacias leiteiras se distribuem por todas as áreas do estado. Da mesma forma, tal informação evidencia que no Ceará parte importante da pecuária leiteira está monopolizada pelo capital industrial.

A Cooperativa Agrícola Mista de Maranguape Ltda tem sede no município de Maranguape, na Região Metropolitana de Fortaleza (RMF), sendo sua produção voltada principalmente para a própria região. No que tange à origem de sua matéria prima destacam-se especialmente produtores locais e dos municípios do Sertão Central do estado (MENDES, 2006).

A Betânia Lácteos é líder no segmento de leite longa vida na região Nordeste, ${ }^{15} \operatorname{com} 30$ $\%$ deste mercado e $13 \%$ do segmento de iogurtes, ${ }^{16}$ e foi eleita a quarta melhor empresa de laticínios pelo $12^{\circ}$ Anuário do Agronegócio de $2016^{17}$ e a sexta maior empresa no ramo de leite

\footnotetext{
${ }^{13}$ Para a redação da presente seção, a metodologia predominante foi a leitura e seleção de parte do material organizado na hemeroteca.

14 CE: Parmalat deve estimular aumento na produção. MilkPoint. 09 maio 2007. Disponível em: $<$ https:/www.milkpoint.com.br/noticias-e-mercado/giro-noticias/ce-parmalat-deve-estimular-aumento-naproducao-35921n.aspx>. Acesso em: 31 mar. 2018.

${ }^{15}$ FALCÂO, Mariana. Betânia volta a liderança de longa vida no NE. Valor Econômico, Recife, 29 jul. 2015. Disponível em: <https:/valor.globo.com/agronegocios/noticia/2015/07/29/betania-volta-a-lideranca-em-longavida-no-ne.ghtml> Acesso em: 13 jul. 2020.

${ }^{16}$ CAVALCANTE, Irna. CBL Alimentos muda para Betânia Lácteos e investe R\$ 20 mi no Ceará. O Povo, 10 abr. 2018. Disponível em: <https://www.opovo.com.br/jornal/economia/2018/04/cbl-alimentos-muda-parabetania- lacteos-e-investe-r-20-mi-no-ceara.html>. Acesso em: 13 jul. 2020.

${ }^{17}$ REVISTA GLOBO RURAL. 12 Anuário do Agronegócio. Rio de Janeiro: Editora Globo, 2016.
} 
e derivados do Brasil, em 2018. ${ }^{18}$ Ela possui um portfólio com 80 produtos, incluindo leites pasteurizados, leites longa vida, bebidas lácteas, iogurtes, queijos, requeijões, doce de leite, leite em pó, creme de leite e leite condensado, distribuídos em cinco marcas, sendo que uma delas se confunde com a da própria empresa. As demais são Lebom, Jaguaribe, Cilpe e Latimilk, ${ }^{19}$ sendo que algumas destas guardam o nome de empresas que foram adquiridas pela Betânia, especialmente desde o final da década de 2000.

Figura 1. Estabelecimento industrial da empresa de laticínios Betânia Lácteos

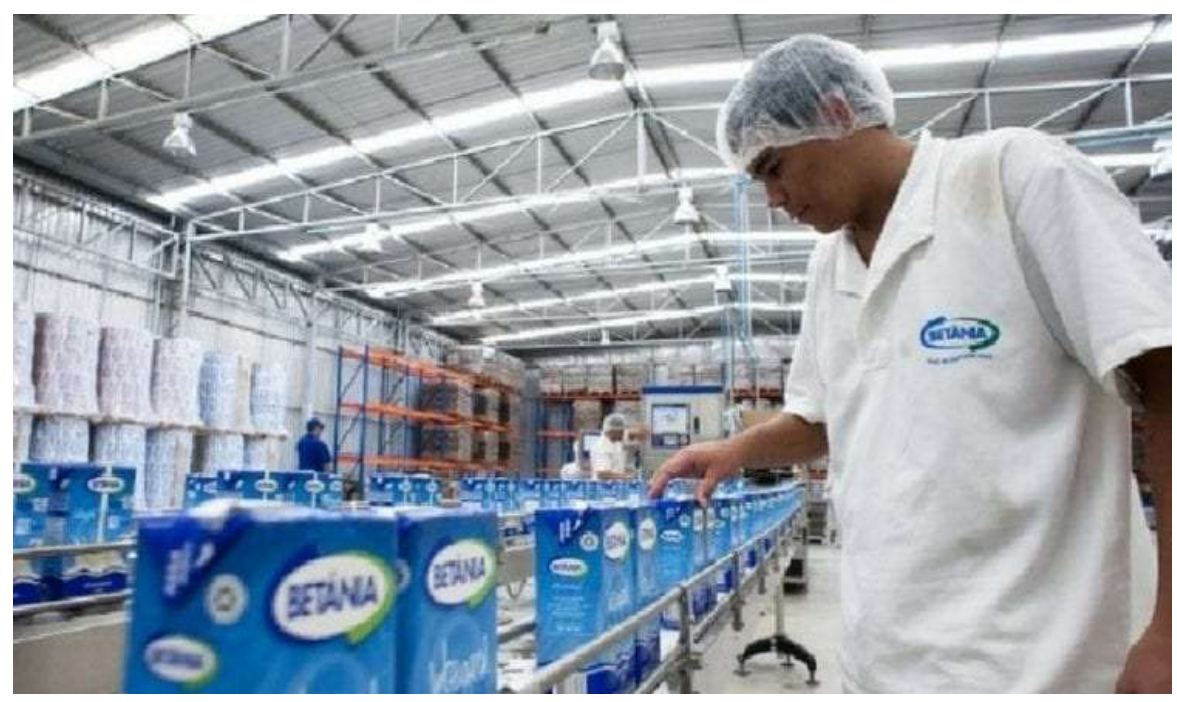

Fonte: Disponível em: https://distribuicao.abad.com.br/industria/cbl-alimentos-muda-para-betanialacteos-e-anuncia-investimentos/. Acesso em: 21 jul. 2020.

Além da distribuição através de suas próprias marcas realizada em mais de 20 mil pontos de venda, ${ }^{20}$ parte de sua produção é voltada a outras empresas, para as quais embala com suas

\footnotetext{
${ }^{18}$ REVISTA EXAME. Melhores e Maiores: as 1000 maiores empresas do Brasil. São Paulo: Editora Abril, 2019.

${ }^{19}$ Betânia aplica R 25 mi em fábrica de Morada Nova. Diário do Nordeste, Fortaleza, 24 maio 2017. Disponível em: $<$ https://diariodonordeste.verdesmares.com.br/negocios/betania-aplica-r-25-mi-em-fabrica-de-morada-nova1.1758989>. Acesso em 13 jul. 2020.

${ }^{20}$ NOGUEIRA, Adriano. Fundo compra $20 \%$ da Betânia. O Povo, Fortaleza, 02 jun. 2017. Disponível em: $<$ https://www. opovo.com.br/jornal/economia/2017/06/fundo-compra-20-da-betania.html $>$ Acesso em: 14 jul. 2020.
} 
respectivas marcas, tal como ocorre com a multinacional francesa Danone, com sede no Distrito Industrial no município de Maracanaú, na RMF. ${ }^{21}$

Tanto a obtenção da matéria-prima quanto o mercado da empresa revelam uma atuação regional, embora sua relevância no setor seja nacional, uma vez que se destaca entre as melhores empresas produtoras de laticínios do Brasil. ${ }^{22}$ A empresa capta 830 mil litros de leite por dia de seus 3.500 fornecedores espalhados por cerca de 130 municípios em todo o Nordeste, ${ }^{23}$ especialmente do próprio Ceará, mas também de Pernambuco, Sergipe, Bahia e Paraíba. ${ }^{24}$ São cinco unidades industriais distribuídas pelos estados do Ceará, Pernambuco, Paraíba e Sergipe, além de 10 centros de distribuição no Nordeste. ${ }^{25}$

A unidade fabril cearense da Betânia Lácteos está localizada na região do baixo Jaguaribe, no município de Morada Nova, cerca de 200 km de Fortaleza, capital do estado, onde sua sede está situada, o que também evidencia as relações campo-cidade de grande complexidade, devido aos fluxos de várias naturezas, incluindo os de informações associados aos processos de gestão corporativa. De suas redes políticas (SILVA, 2018) poderíamos citar o Sindicato da Indústria de Laticínios e Produtos Derivados no Estado do Ceará (Sindlaticínios), presidido por um importante executivo da Betânia Lácteos ${ }^{26}$, e a Câmara Temática do Leite e Derivados, da Agência de Desenvolvimento do Estado do Ceará S.A. (Adece), ${ }^{27}$ pertencente à Secretaria de Desenvolvimento Econômico, da qual o Sindlaticínios é entidade participante, ambos localizados na cidade de Fortaleza.

\footnotetext{
${ }^{21}$ FALCÂO, Mariana. Betânia volta a liderança de longa vida no NE. Valor Econômico, Recife, 29 jul. 2015. Disponível em: https://valor.globo.com/agronegocios/noticia/2015/07/29/betania-volta-a-lideranca-em-longavida-no-ne.ghtml. Acesso em 14 jul. 2020.

${ }^{22}$ MILKPONT. Levantamento TOP 100 2017: os 100 maiores produtores de leite do Brasil. 2017. Disponível em: <https://www.milkpoint.com.br/top100/2017/ebook/top100-2017.pdf>. Acesso em: 30 mar. 2018.

${ }^{23}$ CAVALCANTE, Irna. CBL Alimentos muda para Betânia Lácteos e investe R\$ 20 mi no Ceará. O Povo, 10 abr. 2018. Disponível em: <https://www.opovo.com.br/jornal/economia/2018/04/cbl-alimentos-muda-parabetania- lacteos-e-investe-r-20-mi-no-ceara.html>. Acesso em: 13 jul. 2020.

${ }^{24}$ ROCHA, Alda do Amaral. Com Arlon, Betânia planeja fazer investimento de 100 milhões. Valor Econômico, 14 jul. 2017. Disponível em: <https://valor.globo.com/agronegocios/noticia/2017/07/14/com-arlon-betaniaplaneja-fazer-investimentos-de-r-100-milhoes.ghtml>. Acesso em: 13 jul. 2020.

${ }^{25}$ Disponível em <https://www.betanialacteos.com.br/quem-somos $>$. Acesso em: 13 jul. 2020.

${ }^{26}$ Disponível em: <https://www.portaldaindustria.com.br/cni/institucional/sindicatos-por-estado/?estado=CE $>$. Acesso 14 jul. 2020.

27 “As Câmaras Setoriais e Temáticas são órgãos de caráter consultivo e propositivo, compostas por representantes das entidades privadas, organizações não governamentais e órgãos públicos relacionados aos respectivos segmentos produtivos. Os integrantes das Câmaras atuam em colegiado, identificando as potencialidades e removendo as dificuldades com vistas ao desenvolvimento econômico das atividades produtivas no Ceará". Disponível em: <https://www.adece.ce.gov.br/camaras/ct-leite/>. Acesso em: 14 jul. 2020.
} 
Para o caso do grupo de Abate e Preparação de Produtos de Carne e de Pescado, que inclui a classe de Abate de Aves e Outros Pequenos Animais e Preparação de Produtos de Carne, vamos exemplificar as relações campo-cidade a partir da Companhia de Alimentos do Nordeste (Cialne), que se destaca na avicultura cearense e abastece o mercado das regiões Nordeste e Norte do país.

Maior empresa da avicultura do Ceará, uma das líderes do setor no Nordeste, ${ }^{28}$ a Cialne, fundada em 1966, tem 53 unidades produtivas distribuídas pelos estados do Ceará, Maranhão e Piauí. Sua sede corporativa localiza-se na cidade de Fortaleza. Além dessa, são granjas de avós, granja de matrizes, granja de frangos, incubatórios, fábrica de ração, uma unidade industrial de abate de frangos, produção de leite, laticínio, criação de ovinos, cria e recria de gado. Todos esses fixos estão distribuídos por diferentes municípios num raio médio de 600 quilômetros de Fortaleza, com o máximo de mil quilômetros entre o frigorífico e mercados consumidores. No Ceará os fixos da empresa distribuem-se especialmente por Fortaleza, Maranguape, Caucaia, Aquiraz, Paracuru e São Gonçalo do Amarante, estes municípios todos na RMF, além de Ubajara, Umirim, Guaiúba, entre outros. No Maranhão, as granjas de frango e a fábrica de ração abastecem as unidades da região. No Piauí possui um abatedouro próprio (Dudico), uma fábrica de ração e uma granja de frangos. ${ }^{29}$

É de grande expressão a quantidade de fluxos que se dá entre estes diferentes fixos associados à empresa: trabalhadores, matérias-primas, insumos (ração, vacinas etc.), maquinários, informações, capital etc., evidenciando uma complexa rede geográfica da empresa, que é multiescalar e conectada ao campo e à cidade por meio de seus processos produtivos.

No grupo Fabricação de outros produtos alimentícios, a empresa agroindustrial que serve de exemplo é a Ducoco Produtos Alimentícios S.A., que atua na produção e transformação industrial do coco. Seu portfólio soma cerca de 130 produtos, sendo que os principais são água de coco, leite de coco, coco ralado, óleo de coco, isotônicos e sucos de frutas acrescidos de água de coco. É uma das maiores exportadoras de água do coco do Brasil.

\footnotetext{
${ }^{28}$ VALOR 1000. 1000 Maiores Empresas e as campeãs em 25 setores e 5 regiões. Rio de Janeiro: Grupo Globo, 2019.

${ }^{29}$ CIALNE. Disponível em: <http://www.cialne.com.br/>. Acesso em: 14 jul. 2020; DINHEIRO RURAL. https://www.dinheirorural.com.br/secao/capa/sem-tempo-para-descansarr. Acesso em: 20 jun. 2020.
} 


\section{Figura 2 - Alguns dos principais produtos do portfólio da Ducoco: água de coco envasada, leite de coco, coco ralado e óleo de coco.}

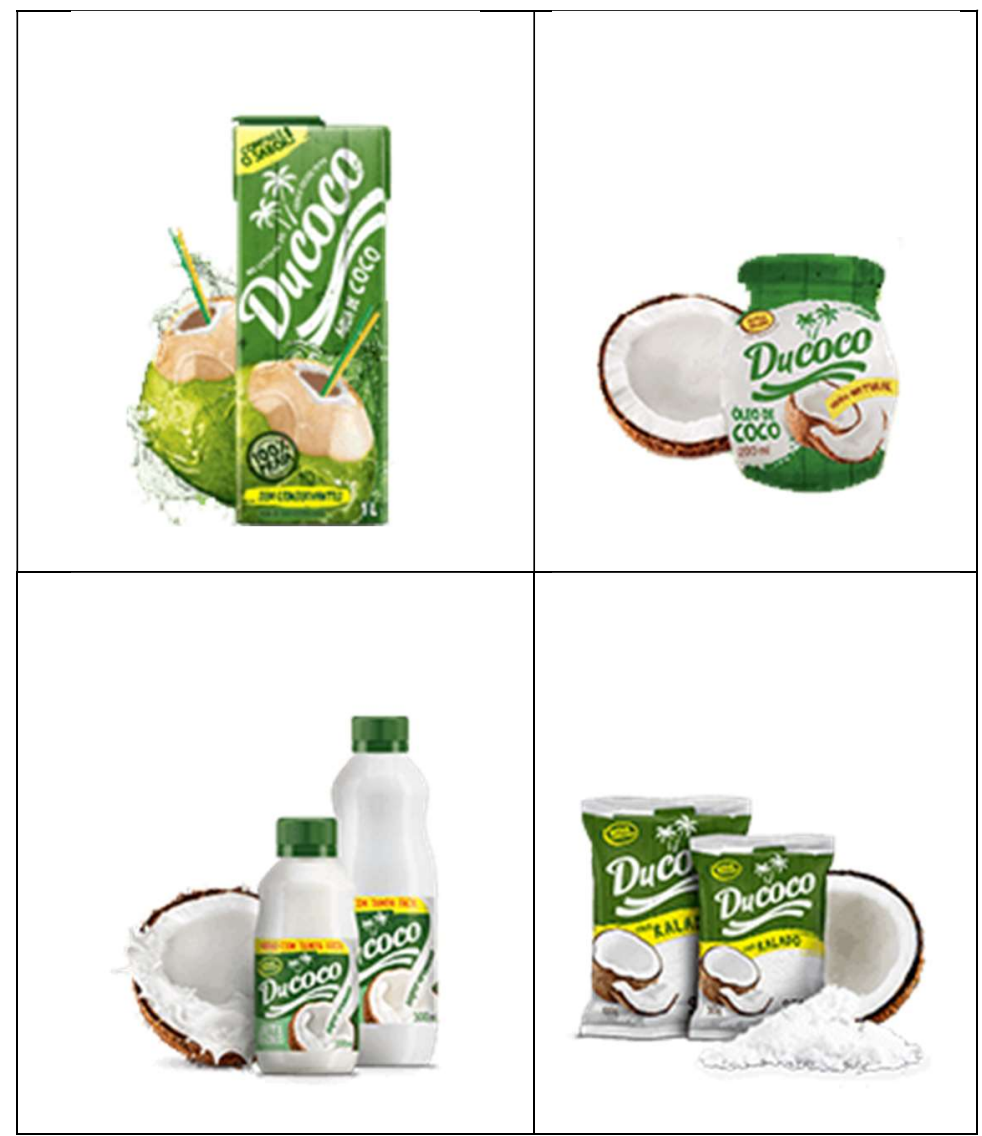

Fonte: Disponível em: <http://www.ducoco.com.br/produtos/>. Acesso em: 21 jul. 2020

Fundada no início dos anos 1980, é hoje uma das maiores empresas do segmento de produtos à base de coco no país. A Ducoco possui sete fazendas distribuídas pelos municípios de Itapipoca, Itarema e Camocim (CE), ${ }^{30}$ duas unidades industriais (Itapipoca/CE e Linhares/ES), três centros de distribuição (Itapipoca/CE, Linhares/ES e Barueri/SP) e uma sede corporativa na cidade de São Paulo, localizada no principal centro financeiro do país. ${ }^{31}$

Apesar de produzir parte importante de todo o coco que processa, aproximadamente $50 \%$ vêm de cerca de 800 produtores espalhados por várias áreas agrícolas, especialmente de

\footnotetext{
${ }^{30}$ Dados do ano de 2009 mostravam que a empresa concentrava mais de 10 mil hectares de terra. Disponível em: $<$ http://diariodonordeste.verdesmares.com.br/ducoco-alimentos-ativa-ha-26-anos-1.101512>. Acesso em 22 jul. 2020.

31 RODRIGUES, Jéssica. Beneficiamento do coco amplia setor industrial. Diário do Nordeste Online, Fortaleza, 22 fev. 2013. Disponível em: <http://diariodonordeste.verdesmares.com.br/cadernos/regional/ beneficiamento-dococo-amplia-setor-industrial-1.195825>. Acesso em: 01 abr. 2018
} 
municípios litorâneos cearenses, tais como Acaraú, Amontada, Beberibe, Camocim, Cascavel, Itapipoca, Itarema, Paraipaba, Pentecoste e Trairi, mas também do Rio Grande do Norte, Paraíba, Pernambuco e Bahia, ${ }^{32}$ evidenciando, assim, uma grande quantidade de fluxos entre estas áreas e a cidade de Itapipoca, local da transformação industrial.

Tais fluxos não são somente da produção agrícola, mas também de trabalhadores com distintos níveis de formação, de inúmeros produtos associados ao consumo produtivo (SANTOS, 1988) do agronegócio (ELIAS, 2015), tais como fertilizantes, agrotóxicos, mudas, máquinas agrícolas etc.

Se pensarmos nas várias etapas do processo de produção de uma empresa como a Ducoco, fica fácil perceber as inúmeras relações campo-cidade que se processam, das áreas de produção agrícola para as unidades industriais, para os centros de pesquisa, para o consumo produtivo (produtos e serviços), para a comercialização e consumo dos produtos, para os fixos associados à logística voltados à exportação etc. Para esse último caso, diferente das outras empresas até aqui apresentadas, a Ducoco tem parte importante de sua produção voltada para exportação, notabilizando-se por ser uma das maiores exportadoras de água de coco do país, sendo que o escoamento se dá a partir do Porto do Pecém, localizado na RMF. Tudo isto, por si só, mostra que a empresa possui uma densa, complexa e multiescalar rede geográfica, que inclui campo e cidades de diferentes dimensões.

Nosso último exemplo das relações campo-cidade, a partir das grandes empresas agroindustriais cearenses, pertence ao grupo de Moagem, fabricação de produtos amiláceos e de alimentos para animais, trata-se da Companhia Industrial de Óleos do Nordeste (Cione), associada a uma das mais tradicionais culturas cearenses, a cajucultura, de grande importância econômica e social para o estado.

No Brasil, a produção de castanha de caju concentra-se na região Nordeste, especialmente nos estados do Ceará, Rio Grande do Norte e Piauí, constituindo um produto de elevada importância no PIB desses estados, assim como de suas respectivas pautas de exportação. A cajucultura abrange as atividades agrícola e industrial. O Ceará é o principal produtor do país, somando também o maior parque industrial de beneficiamento do produto, algo em torno de $90 \%$ da capacidade instalada no Nordeste (SINDICAJU, 2016). Dados da Associação dos Cajucultores do Ceará (ASCAJU) indicam que o estado possui em torno de 500

\footnotetext{
${ }^{32}$ Idem.
} 
mil hectares de cajueiros, distribuídos em várias áreas do Estado, sendo que 70\% da área plantada está nas mãos de pequenos produtores rurais com áreas em torno de 10 a 20 hectares. Quanto aos empregos na indústria, são cerca de 25 mil na cidade, sendo que o setor ainda se coloca em segundo lugar na pauta de exportação. ${ }^{33}$

No intervalo de algumas décadas, a produção agrícola de caju passou de uma produção basicamente extrativista para uma atividade agroindustrial. Localiza-se principalmente ao longo da faixa litorânea, especialmente na faixa leste, destacando-se municípios como Beberibe, Cascavel, Aracati, entre outros, e hoje disputa terras com outras culturas também em expansão, como a do coco.

O produto da atividade industrial do caju de maior valor comercial é, sem dúvida, a amêndoa da castanha de caju. Mas o líquido resultante do processamento da casca da castanha também tem grande importância comercial, pois é utilizado como matéria-prima para industrialização de uma gama de produtos (tintas, vernizes, lubrificantes, inseticidas etc.)

O ramo industrial da cajucultura é bastante concentrado. Hoje são perto de dez empresas que dominam o processamento industrial do caju, sendo a Cione um destaque entre estas. ${ }^{34}$ Fundada no início dos anos 1960, atua tanto na produção de caju, quanto na sua transformação industrial e na comercialização de castanhas de caju, constituindo-se uma das maiores plantadoras de cajueiros do mundo e a maior exportadora de castanha de caju não só do estado, mas do Brasil. De sua produção, $95 \%$ são destinados à exportação. ${ }^{35}$ De acordo com dados do Ministério do Comércio Exterior (MDIC, 2018), figura entre as vinte maiores exportadoras do Ceará no ano de 2017.

A Cione possui quatro fazendas distribuídas nos estados do Ceará e do Piauí, das quais se origina parte importante da matéria-prima que processa. Estas somam mais de 70 mil hectares, sendo perto de 60 mil plantados com cajueiros, incluindo o maior projeto de cajueiro

\footnotetext{
33 ASCAJU e SINCAJU pedem audiência a Assembleia para discutir Cajucultura. Comunicação FAEC/SENAR, 26 jul. 2019. Disponível em: <http://faec.org.br/novo/ascaju-e-sincaju-pedem-audiencia-a-assembleia-paradiscutir-cajucultura/>. Acesso em: 14 jul. 2020.

${ }^{34}$ Fonte: dados do site. Além da Cione destacaríamos entre as mais importantes agroindústrias da cajucultura no Ceará as empresas: Amêndoas do Brasil; Iracema Indústria e Comércio de Castanhas de Caju Ltda (ambas em Fortaleza); Companhia Brasileira de Resinas - Resibras (Forquilha); Copan - Agroindustrial LTDA (Jaguaruana) e Usibrás - Usina Brasileira de Óleos e Castanha Ltda (Aquiraz) (SINDICAJU, 2016).

${ }^{35}$ Disponível em: <https://www.cione.com.br/sobre-ns>. Acesso em: 16 mar. 2018.
} 
anão precoce do estado do Ceará. ${ }^{36}$ Sua sede administrativa e sua unidade industrial localizamse na cidade de Fortaleza.

Além das áreas de produção agrícola, da indústria, da sede corporativa, podemos indicar outros fixos ligados diretamente à cajucultura e, portanto, de grande relevância à produção da Cione, e que também nos servem para evidenciar as relações campo-cidade promovidas a partir da empresa. Entre estes podemos citar a sede da Embrapa na cidade de Fortaleza, assim como o seu campo experimental no município de Pacajus. Boa parte das novas áreas de produção da Cione são realizadas utilizando os clones de cajueiro anão precoce, tal como ocorre nas suas plantações no Piauí.

Das redes políticas associadas à cajucultura vêm outros exemplos importantes de fixos entre os quais se dão inúmeros fluxos campo-cidade associados à Cione, tal como o Sindicato das Indústrias de Castanha de Caju (Sindicaju), cuja sede localiza-se no próprio prédio da Federação das Indústrias do Estado do Ceará (FIEC), na cidade de Fortaleza, ou ainda a Câmara Temática do Caju, vinculada à Adece. ${ }^{37}$ Podemos citar também o Banco do Brasil e o Banco do Nordeste como os principais agentes financeiros associados à cajucultura, já que são responsáveis por grande parte dos empréstimos para custeio e produção até hoje realizados pela empresa. Os dados até aqui apresentados sobre a Cione mostram, então, uma complexa rede geográfica, que une campo e cidade em múltiplas escalas.

\section{CONSIDERAÇÕES FINAIS}

Diante do exposto, muito embora a atividade agroindustrial cearense seja majoritariamente formada por pequenos estabelecimentos, a força das grandes empresas é inegável, evidenciando-as como variável-chave para a compreensão de inúmeros processos inerentes ao agronegócio globalizado no Ceará.

Entendemos que as redes geográficas tecidas por essas empresas, considerando seus diversos fixos e fluxos, sistemas de objeto e sistemas de ação (SANTOS, 1988, 1996), revelam,

\footnotetext{
${ }^{36}$ Espécies de caju resultantes das pesquisas da Empresa Brasileira de Pesquisa Agropecuária (Embrapa Agroindustrial), localizada na cidade de Fortaleza, a partir de melhoramento genético. São mais produtivas e produzem em menor tempo. Disponível em: <https://www.embrapa.br/busca-de-noticias//noticia/2361282/pequeno-notavel-cajueiro-anao-precoce-e-produtivo-apos-tres-anos-de-seca>. Acesso em: 14 jul. 2020.

37 A Câmara Temática do Caju é composta por representantes de entidades privadas, de organizações nãogovernamentais e órgãos públicos envolvidos com o setor. Disponível em: $<$ https://www.adece.ce.gov.br/camaras/ct-caju/>. Acesso em: 14 jul. 2020.
} 
entre outros, parte importante das inúmeras relações campo-cidade associadas ao agronegócio de maneira geral, aqui incluso os associados às agroindústrias.

Por outro lado, evidenciou-se também que parte da produção agropecuária cearense está fortemente monopolizada pelo capital industrial. Lembrando Oliveira (2016), a agricultura sob o capitalismo monopolista mundializado estrutura-se, entre outros, a partir da formação das empresas monopolistas. Essas controlam a produção e se articulam através de dois processos monopolistas territoriais no comando da produção agropecuária e florestal mundial: a territorialização dos monopólios e a monopolização do território.

Ambos os processos podem ser observados para as empresas citadas, dado que atuam, simultaneamente, tanto no controle da propriedade privada da terra, do processo produtivo no campo e do processamento industrial da produção agropecuária, quanto no controle de mecanismos de subordinação de camponeses e capitalistas produtores agropecuários.

Evidente está, então, que a agropecuária cearense, vem passando por muitas metamorfoses nas últimas três décadas, com a difusão do agronegócio globalizado, através dos processos de reestruturação produtiva, representando um crescente domínio do neoliberalismo e do capital financeiro.

\section{REFERÊNCIAS}

ABU-EL-HAJ, J.. Neo-Desenvolvimentismo no Ceará: a Política Industrial do Governo Tasso. Revista de Economia do Nordeste, Fortaleza, v. 28, n.3, p. 325-345, jul. 1997.

AMORA, Z. B. Aspectos históricos da industrialização do Ceará. In: SOUZA, S. (Org.). História do Ceará. 2. ed. Fortaleza: Fundação Demócrito Rocha, 1994. p. 117-124.

BRASIL. Lei no 3.995, de 14 de dezembro de 1961. Aprova o Plano Diretor da SUDENE, para o ano de 1961, e dá outras providências, Brasília: Presidência da República, 1961. . Ministério do Trabalho e Emprego. Relação Anual de Informações Sociais RAIS. Disponível em: <http://bi.mte.gov.br/bgcaged/ login.php>. Acesso em 10 fev. 2018. . Ministério da Indústria, Comércio Exterior e Serviços. Empresas brasileiras exportadoras e importadoras. Disponível em: <http://www.mdic.gov.br/ comercioexterior/estatisticas-de-comercio-exterior/empresas-brasileiras-exportadoras-e-importadoras $>$. Acesso em: 28 mar. 2018.

CORRÊA, R. L. Trajetórias geográficas. 7. ed. Rio de Janeiro: Bertrand Brasil, 2014. 302p. 
FERREIRA, A. O crescimento recente da economia cearense. Revista de Economia do Nordeste, Fortaleza, v. 26, n. 2, p. 157-180, abr. 1995.

ELIAS, D. A agropecuária do Estado do Ceará no contexto da globalização. In: AMORA, Z. B. (Org.). Ceará: enfoques geográficos. Fortaleza: Funece, 1999. p. 43-72. . A modernização da produção agropecuária. In: ELIAS, D. (Org.). O novo espaço da produção globalizada: Baixo Jaguaribe (Ce). Fortaleza: Funece, 2002a. p. 281-355. . Integração competitiva do semiárido cearense. In: ELIAS, D.; FURTADO, J. L. S. (Orgs.). Modernização excludente. Fortaleza: Demócrito Rocha, 2002b. p.15-43.

. Globalização e agricultura: a região de Ribeirão Preto. São Paulo: Edusp, 2003a.

. Desigualdade e pobreza no espaço agrário cearense. Mercator, Fortaleza, v. 2, n.3, p. 61-69, 2003b.

. Redes agroindustriais e urbanização dispersa no Brasil. Scripta Nova, Barcelona, v. 12, n. 270, p. 74-96, ago. 2008.

. Globalização, agricultura e urbanização no Brasil. Acta Geográfica, Boa Vista, v. 1, p. 13-32, nov. 2013.

. Consumo produtivo em Regiões do Agronegócio do Brasil. In: BELLET, C.; MELAZZO, E. S.; SPOSITO, M.E.B.; LLOP, J. M. (Orgs.). Urbanización, producción y consumo em ciudades medias/intermedias. Lleida: Edicions de La Universitat de Lleida, 2015. p. 35-56.

Agronegócio globalizado: do campo a metrópole. In: FERREIRA, A.; RUA, J.; MATTOS, R. C. (Orgs.). O espaço e a metropolização: cotidiano e ação. Rio de Janeiro: Consequência, 2017. p. 587-509.

IBGE. Instituto Brasileiro de Geografia e Estatística. Introdução à Classificação Nacional de Atividades Econômicas - CNAE versão 2.0. IBGE: Rio de Janeiro, 2007. Disponível em: < https://concla.ibge.gov.br/images/concla/documentacao/CNAE20_ Introducao.pdf $>$. Acesso em: 10 jan. 2020.

Pesquisa Industrial Anual - PIA. Rio de Janeiro: IBGE, 2017. Disponível em: $<$ https://biblioteca.ibge.gov.br/visualizacao/periodicos/1719/pia2017v36 n1 empresainformativo.pdf>. Acesso em: 12 jan. 2020. 
MENDES, M. C. Metropolização e Indústria: Maranguape no Contexto da Região Metropolitana de Fortaleza- Ce. 2006. 160 f. Dissertação (Mestrado em Geografia) - Centro de Ciência e Tecnologia, Universidade Estadual do Ceará, Fortaleza, 2006.

OLIVEIRA, A. U. Agricultura e indústria no Brasil. Campo-Território, v. 5, n.10, p. 5-64, set. 2010 .

. A Mundialização da agricultura brasileira. São Paulo: Iandé Editorial, 2016.

OLIVEIRA, Francisco. Elegia para uma re(li)gião: SUDENE, Nordeste, planejamento e conflito de classes. 6. ed. Rio de Janeiro: Paz e Terra, 1993.

SANTOS, M. Metamorfose do espaço habitado: fundamentos teóricos e metodológicos da Geografia. São Paulo: Hucitec, 1988. 132p.

. Técnica, espaço e tempo: globalização e meio técnico-científico-informacional. São Paulo: Hucitec, 1994. 190 p.

A natureza do espaço: técnica e tempo, razão e emoção. São Paulo: Hucitec, 1996. $308 \mathrm{p}$.

SILVA, C.A.F. Da política à rede política territorial. In: ELIAS, D; PEQUENO, R (Orgs.). Tendências da Urbanização Brasileira: novas dinâmicas de estruturação urbano-regional. Rio de Janeiro: Letra Capital, 2018. cap.6, p. 167-190. 